\title{
Kernos
}

Revue internationale et pluridisciplinaire de religion grecque antique

$10 \mid 1997$

Varia

\section{J.-M. NIETO IBÁÑEZ, Estudios de religión y mito en}

\section{Grecia y Roma}

\section{Angel Ruiz Pérez}

ERL : http://journals.openedition.org/kernos/681

DOI : 10.4000/kernos.681

ISSN : 2034-7871

\section{Éditeur}

Centre international d'étude de la religion grecque antique

\section{Édition imprimée}

Date de publication : 1 janvier 1997

Pagination : $343-345$

ISSN : 0776-3824

Référence électronique

Angel Ruiz Pérez, " J.-M. NIETo IBÁÑEz, Estudios de religión y mito en Grecia y Roma », Kernos [En ligne], 10 | 1997, mis en ligne le 12 avril 2011, consulté le 24 septembre 2020. URL : http:// journals.openedition.org/kernos/681; DOI : https://doi.org/10.4000/kernos.681 
capitales pour les titres d'ouvrages (p. 230), la lourdeur des mentions bibliographiques. Un exemple éclairant se trouve p. 106, n. 4 « on peut lire dans le Dict. des Antiq. grecques et romaines de DAREMBERG et SAGLIO, extrait de l'article de F. LENORMANT : '...' op. cit., T. I, $1^{\mathrm{e}}$ part., s.v. Baetylia p. 644a). " En outre, des indications telles que «le $12^{\mathrm{e}}$ tirage de l'édition Villeneuve aux Belles Lettres, tirage revu et corrigé par J. Hellegouarc'h en 1990 » (p. 63, n. 3) ou « la note d'A. Bellesort dans son édition de l'Énéide de Virgile, aux Belles Lettres, à propos du vers 54 du chant viII " (p. 76, n. 3) sont longues et inutiles. À côte de cette volonté de citer le dernier état d'une publication, l'A. recourt à des éditions anciennes (p. ex. p. 105, n. 4 : Photios, cité uniquement d'après l'édition de BEKKER). Enfin, la bibliographie finale manque d'ordre et de précision. On s'étonnera notamment de trouver Ennius cité d'après le Recueil de textes latins arcbaïques de ERNOUT - dont il faut citer la nouvelle édition de 1973, non celle de 1957 -, alors qu'il convient de se référer à la troisième édition de VAHLEN ou à celle de SKUTSCH (Oxford, 1985). De même, la section « Manuels, dictionnaires et encyclopédies » comporte trop d'ouvrages, dont certains ne semblent pas avoir été exploités dans le commentaire. Un tri eût certainement été nécessaire, ainsi qu'une toilette typographique. Dans cette liste, on trouve l'ouvrage ancien de GRUPPE (Munich, 1906), certes encore utile, mais on cherche en vain celui de M.P. NILSSON (Munich, 1967-19733) dans la même série du Handbuch der Altertumswissenscbaft. Les ouvrages de DETIENNE et de DUMÉZIL cités dans cette subdivision sont-ils bien à leur place ? On eût aimé aussi connaître le nom du ou des auteurs de la concordance aux Mythographi Vaticani I et II (Turnhout, 1987), présentée simplement comme émanant de l'Université catholique de Louvain (en grandes capitales, comme les noms d'auteurs). Pour les « petits commentateurs " de Virgile, cités p. 230, on doit à présent citer le recueil de I. BARABINO, A.V. NAZZARO et A. SCIVOLETTO (éds), Interpretationes Vergilianae Minores, I, Gênes, 1991 (Pubbl. del dipart. di arcb., fil. cl. e l. trad., n.s. 137).

Ces remarques n'ont pas pour but de dévaloriser le travail, méritoire, d'un traducteur, qui est de surcroît un pionnier. Elles voudraient seulement attirer l'attention sur la nécessité de fournir avec une traduction les éléments nécessaires à l'intelligence du texte, tous ces éléments, certes, mais seulement ces éléments. Une note précise et concise vaut mieux qu'un fatras d'érudition qui égare le lecteur dans un dédale de propos superflus, sans lui apporter, en définitive, la précision qui l'aurait éclairé. Ajoutez, quelquefois, et souvent effacez, disait Boileau.

Bruno ROCHETTE (Université de Liège)

\author{
Jesús-María Nieto IBÁÑez (coord.), Estudios de religión y mito en \\ Grecia y Roma. X Jornadas de Filología Clásica de Castilla y León, León, \\ Universidad, Secretariado de Publicaciones, 1995. 1 vol. $17 \times 24 \mathrm{~cm}, 295$ p., ill. \\ ISBN : 84-7719-517-X
}

Les royaumes de Castille et León ont occupé le centre géographique et culturel de l'Espagne, surtout pendant le Moyen âge et la Renaissance, grâce à leur histoire singulière, comme on le voit par l'existence de deux des Universités les plus anciennes d'Europe, celles de Salamanca et de Valladolid, auxquelles on a récemment ajouté celles de León et de Burgos. Ces dix dernières années, les Départements de Philologie Classique de ces Universités ont été chargés d'organiser des Colloques sur un thème particulier; le dixième, qui a eu lieu à León, a été consacré à la religion et mythologie classiques, et les Actes en ont été édités avec une rapidité surprenante, qui permet d'expliquer quelques errata et un saut dans l'ordre alphabétique de la bibliographie des pages 32-33. On distingue cinq groupes thématiques : 


\section{Religion et mytbologie grecques des époques archaique et classique}

Deux contributions peuvent être signalées comme les plus importantes du livre, celle de E. SUÁREZ DE LA TORRE (La función del mito en la religión griega, p. 15-35), un exposé général très éclairant des rapports entre religion et mythe, qu'il applique concrètement aux cultes de Patras, par l'analyse d'un texte de Pausanias (VII, 19, 1-20), et celle de P. NIETO HERNÁNDEZ (Mensajeros divinos en Homero; Iris y Hermes en la Iliada y en la Odisea, p. 37-52), qui apporte une importante contribution à l'étude de la fonctionnalité respective des deux dieux et son exclusivité dans chaque poème homérique; l'article de A.M. MARTín RODRíguez (Paralelos folklóricos en la figura de Aquiles, p. 247-257) fait des parallèles entre le mythe d'Achille et d'autres, comme celui de la Belle au Bois dormant.

\section{De l'Antiquité grecque tardive}

L'éditeur du livre, J.-M. NIETO IBÁÑEZ envisage (Troya y Sícimos: la épica bomérica de Teódoto el judio, p. 53-57) les rapports entre le judaïsme et le monde hellénistique dans le domaine du mythe; M. BRIOSO SÁNCHEZ (Poesía y religión en la antigüedad griega tardía, p. 59-87) étudie l'interaction de quelques poèmes païens et chrétiens d'époque post-hellénistique; G. MOROCHO GAYO (Mito griego y literatura cristiana: los Reyes Magos, p. 103-122) analyse les aspects mythiques des textes apocryphes sur la Nativité, et M.C. BARRIGÓN FUENTES (La utilización del mito en la obra de Artemidoro, p. 89-101) cherche les mythes cités dans l'Oneirocritica de cet auteur.

\section{Religion romaine et monde médiéval}

M.-A. MARCOS CASQUERO parcourt (Creencias religioso-supersticiosas del mundo antiguo relativas al cabello, p. 123-153) les rites de passage et la fonction qu'y remplissent les chevaux; M.A. SÁNCHEZ MANZaNo (Venus grata, p. 155-163); R.M. HERRERA GARCÍA (El vocabulario religioso romano en Isidoro de Sevilla, p. 183-93) étudie les termes religio, superstitio, sacer, sanctus. E. SÁNCHEZ SALOR (Los origenes del cristianismo en Hispania. Los casos de Mérida y León-Astorga, p. 165-181) déborde le thème du colloque avec une étude sur les chrétiens et E. FERNÁNDEZ VALLINA (Mundo, visiones y trasmundo: religiosidad y fantasia en tiempos de transición, p. 195-205) déborde l'antiquité pour étudier le monde du Moyen âge dans la visio Baronti et la visio Wettini.

\section{Mythologie de la Renaissance espagnole}

Dans la médecine : M.J. PÉREZ IBÁÑEZ (Mitos y textos médicos renacentistas, p. 207-219); dans les emblemata: B. ANTÓN MARTíNEz (La mitología en la literatura emblemática del Siglo de Oro: los Emblemata centum regio-politica de J. de Solórzano, p. 221-236); et dans l'épopée parodique : J.M. BALCELls DOMÉNECH (La mitología en la epopeya paródica del siglo XVII, p. 237-246).

$V$. Le mythe et son application littéraire dans le monde moderne

B. ORTEGA VILlARO ( $E l$ mito de Fedra y su transformación en tema literario, p. 259-271) pour Racine, Yourcenar, D'Annunzio, les catalans Espriu et Vilallonga et le dramaturge contemporain Martínez Mediero. A. RuIz SOLA (El mito antiguo y su proyección dramática, p. 273-282) explore avec sensibilité l'arrière-fond mythique de Yerma, un des plus connus des drames de García Lorca. Finalement M.A. LÓPEZ JimENo

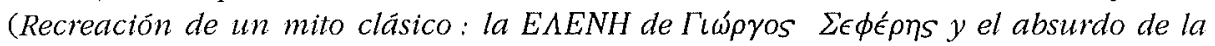
guerra, p. 283-295) s'occupe de la littérature grecque contemporaine. 
La variété thématique fait le grand intérêt que ce recueil pour ceux qui étudient la religion et la mythologie classiques et pour ceux qu'intéressent leurs prolongements en Occident, singulièrement en Espagne.

Ángel Ruiz Pérez

(Université de Valladolid)

Colette Jourdain-Annequin, Corinne Bonnet (éds), II Rencontre Héracléenne. Héraclès, les femmes et le féminin. Actes du Colloque de Grenoble. Université des Sciences Sociales (Grenoble II), 22-23 octobre 1992, BruxellesRome, Brepols, 1996. 1 vol. $25,5 \times 19 \mathrm{~cm}, 291$ p. (Institut Historique Belge de Rome. Études de Pbilologie, d'Archéologie et d'Histoire Anciennes, 31). ISBN: 90-74461-12-3.

L'introduction de Nicole LORAUX au thème du colloque en montre à la fois l'importance et la richesse. Elle évoque en outre l'intensité de ces journées grenobloises, fertiles en discussions. C'est moins la féminité d'Héraclès - un sujet que N. LORAUX a elle-même étudié brillamment - que ses rencontres féminines, femmes et déesses, dans le mythe et dans le culte, auxquelles s'attachent les différentes études du volume. La présentation systématique qui suit espère leur rendre justice derrière la sécheresse de la synthèse toujours trop brève.

Bernard SERGENT (Ces demoiselles de Stymphale) propose une étourdissante comparaison gréco-irlandaise qui replace la quête des pommes des Hespérides, le combat contre les oiseaux de Stymphale et la guerre contre les Amazones dans l'éclairage du rapport d'Héraclès avec Artémis, Arès et Athéna. - Pierre BRulÉ (Héraclès et Augé. À propos des origines rituelles du mythe), parti de la frise de l'autel de Zeus à Pergame où Héraclès espionne Augé en canéphore au sein dénudé, tente d'expliquer cette nudité partielle par une étude attentive du mythe en toutes ses versions et de son arrière-plan rituel, fait de pannycbis, de procession, de chœur et de jeunes filles offertes au regard des hommes qui ne peuvent que constater leur maturité sexuelle. Didier PRALON (Héraclès-Iole), partant d'un schéma matrimonial proposé par G. Dumézil pour baliser le parcours héracléen, passe en revue les traditions principales autour des interventions de Iole et vérifie ainsi la description dumézilienne d'une héroïne passive, surtout intéressante par ce dont elle est l'enjeu. - Françoise LÉTOUBLON (Héraclès et les Thespiades) analyse d'un point de vue littéraire les trois passages qui évoquent l'épisode des Thespiades, ces 50 filles de Thespios auxquelles Héraclès s'unit successivement 50 jours de suite, ou même en une seule nuit : Apollodore (II, 65-66); Pausanias (IX, 27, 6-8); Diodore (IV, 29, 2-6). Le héros s'y situe à la veille de ses principaux exploits, en un épisode qui le fait, démesurément, devenir un homme. Cette prodigieuse fécondation expliquera aussi l'omniprésence d'H. en Béotie, autrement que par le mythe de sa naissance, ainsi que l'hellénisation du monde par ses descendants.

Stefan RITTER (Ercole e Onfale nell'arte romana dell'età tardo-repubblicana $e$ augustea) analyse les représentations d'Héraclès et d'Omphale dans la glyptique, la céramique arétine et dans la poésie romaines de la fin de la République et du début de l'Empire; elles montrent le héros dans sa vie privée, une image de la douceur de vivre et de la puissance de l'amour, à l'écart des vertus traditionnelles ou de toute déclaration d'intention. L'A. refuse donc les lectures « idéologiques » habituelles. - F. WulfF 